[ 260 ]

\title{
The Plague of Octopus on the South Coast, and its effect on the Crab and Lobster Fisheries.
}

\author{
By
}

\author{
Walter Garstang, M.A.
}

Naturalist in charge of Fishery Investigations under the Marine Biological Association.

UNTIL the spring of 1899 the true or common octopus (Octopus vulgaris, L.) had been comparatively rare in the neighbourhood of Plymouth during the past ten or twelve years-i.e. since the opening of the Plymouth Laboratory in 1888. Specimens could only be obtained for the aquarium at long intervals, in spite of the tempting inducements offered to fishermen. As much as ten shillings has more than once been given to fishermen for a specimen of this voracious mollusk. On the other hand, the smaller and less powerful octopod known as Eledone cirrosa was almost always obtainable, and the octopus tank in the aquarium was rarely devoid of several specimens.

In the early part of last year (1899) the situation began to change, and we were for the first time able to keep the tank supplied with a number of true octopus, since which date there has been no difficulty in procuring an unlimited number of specimens, either from the professional fishermen or in the ordinary course of our own fishing operations.

We noticed this increase in the abundance of octopus before there was any means of judging whether it was a purely local phenomenon, or was observable over a wider area. The first specimens were brought to us in January, and from May onwards they were obtained in increasing abundance. Early in the same year, however (though I have no exact record of the date), a visitor from the Channel Islands informed me that the increase of octopus in those islands was so great as to have already caused much damage to the shell fisheries there, since the octopus entered the pots of the fishermen, and destroyed the crabs and lobsters which had been caught.

Later in the year paragraphs began to appear in the newspapers upon the subject, and during the present year (1900) have revealed that the 
increase in octopus on both shores of the English Channel has not only been of a phenomenal character, but has caused widespread disaster to the shell fisheries on the French and English coasts alike. Three of these paragraphs are sufficiently detailed to deserve quotation.

1. From the Western Evening Herald, Plymouth, December 18th, 1899.

\section{"A DEVIL-FISH PLAGUE.}

"A correspondent writes as follows from Rivage de Questichou, a small watering-place on the coast of the Cherbourg promontory: 'For the last two or three months this coast has been visited by a perfect octopus plague. They have quite ruined the fisheries, and many men have laid up their boats in despair. They devour everything, even crabs, and lobsters, and oysters, and all shell fish. The other day a man employed at the large oyster-beds near here told me he had that day found one that had eaten eighteen oysters that tide. The shore is strewn with octopus, and the other morning along highwater mark I counted sixty-eight in a distance of two hundred yards. A friend here measured one, and it was 5 feet 7 inches across the tentacles, but there are far larger ones than that. Some of the suckers are as large as a two-shilling piece. They are most loathsome beasts. Unless the cold winter destroys them, there will be no bathing next summer along this coast.'"

\section{From the Western Morning News, Plymouth, September 18th, 1900.}

"Budleigh Salterton crab and lobster fishery has been a very poor one this season. The failure is attributed by the fishermen in a great measure to octopi. The men say that eight or ten years since it was quite an event to take one of these creatures in their crab or lobster pots, but of late, more especially in the past two summers, their number has increased at an alarming rate, and they are now constantly being taken. The presence of the octopi is believed to be due to the excessive heat of recent summers. Not long since an octopus measuring at least 6 feet, with its tentacles fully extended, was captured off the coast, and they have often been seen close in shore, showing a preference for a pebbly or rocky bottom, and seldom seen where there is much sand."

\section{From the Fishing Gazette, London, October 27th, 1900.}

"Last year and this year the coasts of Brittany have been infested by the cuttlefish (Octopus vulgaris), which had been deserted by them for fifteen years previously. In the Department of Finistère they are so abundant that it is almost impossible to turn over a stone on the beach without finding one or more of the pests. In some places they have been thrown up by the sea after a storm in such quantities that their dead bodies threatened to be a danger to the inhabitants, and hundreds of cartloads had to be carted away and sold as manure.

"In the lobster and crab fishing districts of the coast they have proved so destructive of these fish that the fishermen have been obliged to look to other means of making their living." 
In the Fourteenth Annual Report (for 1899) of the Inspectors of Sea Fisheries (England and Wales), an exceptional abundance of octopus is recorded by the collectors of fishery statistics for Babbacombe, Torquay, Brixham, Yealm, Mevagissey, Cadgwith, and Mousehole, all of which are fishing ports on the south-east coast of Devon and Cornwall. The collector of statistics at Plymouth reports a lack of evidence as to any exceptional prevalence of octopoda off this port, but the information obtained by ourselves leaves no doubt upon the matter.

I have attempted below to throw light upon the three practical aspects of this plague of octopus: (1) its cause, (2) its effects on the shell fisheries, and (3) the possibility of arresting its continuance by remedial measures.

\section{Cause of the Plague.}

There can be no doubt from its widespread character that the plague is due in the first place to an exceptional multiplication of octopus in recent years. There is some evidence, as will be shown below, that the octopus move about in marauding bands; but this is probably a local phenomenon, that cannot account for the exceptional abundance of these creatures on both shores of the Channel.

The suggestion made in the paragraph from the Western Morning News, above cited, is, in my opinion, nearer the truth, viz. that the cause of their prevalence is connected with the heat of recent summers.

We unfortunately know nothing directly concerning the rate of growth of this large octopod. Many small mollusks attain their full size and maturity in their second year, as I have myself shown,* but there is abundant evidence that the larger mollusks require a number of years to attain the same condition. This is well seen in those shellbearing mollusks which form fringes $\dagger$ (varices) on their whorls. The rate of growth in littoral, as well as most land animals, is not even, but is subject to alternating periods of active growth and quiescence, in accordance with the seasons. Consequently the larger fringes on the spiral shells of many mollusks, as well as the "shoots" of an oyster's shell, afford satisfactory indication of the age of these creatures. An oyster $\ddagger$ continues to enlarge his shell by annual "shoots" for four or five years, and then ceases to grow except in thickness. The number of spiny varices on the shells of the various species of Murex is never

* Jour. M.B.A. i., 1890, pp. 447-50.

† Woodward's Manual of Mollusca, 1880, pp. 12, 13, 213.

¥ Oysters may produce spat when two years old, but are most prolific in their fourth and fifth years (fide HoEk. See this Journal, N.S. i. p. 277). 
less than three, and may mount up to seven or eight in certain species (e.g. M. radix, Fischer's Conchyliologie, p. 641, fig. 399). The value, from this point of view, which should be given to the ridges on the shells of ammonites (extinct cuttlefishes) is doubtful. Woodward (loc. cit.) suggests that they may indicate the age of the shell in years (20 to 100); but there is no more ground for this conclusion than there would be for the opinion that the septa in the shell of a Nautilus or a Spirula were of annual formation. Both structures are intimately connected with the growth and support of the body, but their formation cannot be dependent on any annual periodicity of growth, since Spirula at any rate lives in the abysses of the ocean (350 to $950 \mathrm{fms}$.) far below the influence of seasonal changes. On the other hand it is not impossible that the larger and thicker varices which occur at intervals along the shells of certain ammonites may indicate the extent of one year's growth (Fischer and Woodward, loc. cit., pl. iii., figs. 9 and 12). On this basis the age of the specimens figured could be estimated at five or six years.

From the facts recorded above concerning the rate of growth of oysters and the larger gastropods, it seems clear that the larger mollusks require at least three or four years to attain their full normal size. The octopus which have infested our coasts this year have been of various dimensions, but great numbers of them have been of phenomenal size, the arms in many cases attaining a length of 3 feet, and in some a length of $3 \frac{1}{2}$ feet from the mouth to the tip of the arm.

As specimens exceeding these in size are of very rare occurrence, we may assume provisionally that the age of the oldest specimens is at least three or four years, and, upon Woodward's theory of cephalopod growth, may far exceed that limit. The case of Spirula seems to me to be alone sufficient to discredit the accuracy of Woodward's theory; and a maximum age of seven or eight years for the largest specimens of octopus caught this year is the utmost that I should be prepared to assign from the analogy of other mollusks.

These estimates are probably sufficiently accurate to support the view that the plague of octopus may be traced to the influence on the reproduction of this species of the exceptionally favourable conditions which prevailed in 1893. If reference be made to the third volume of this Journal (pp. 210,211) it will be seen that the conditions which prevailed in that year on our southern shores, as well as on the coasts of France, were extraordinarily favourable* for the reproduction of marine animals, and resulted in a great increase of the smaller mollusks, hydroids, and

* The spring quarter was the warmest recorded in our islands for at least thirty-three years, and was succeeded by a hot, calm summer (see this Journal, vi. p. 68, Table G).

NEW SERIES. - VOL. VI. NO. 2 .

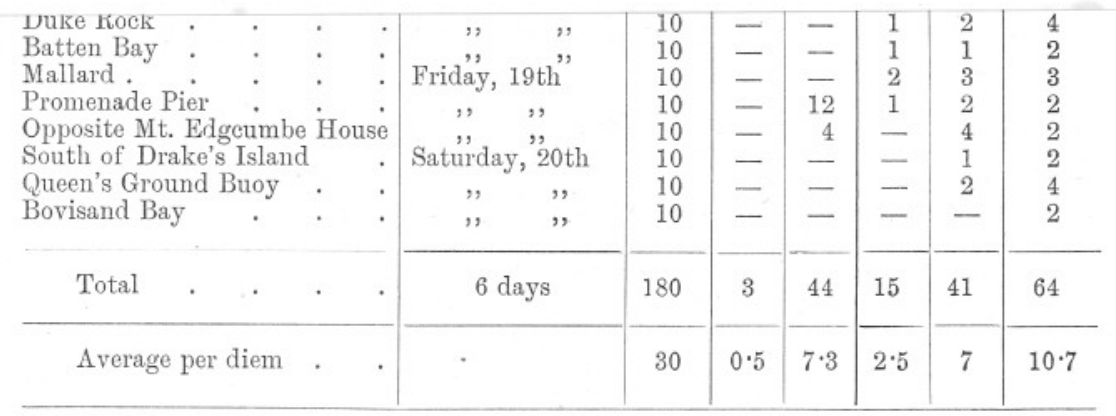

It will be seen that in Plymouth Sound, inside the Breakwater, the fisherman set thirty baited crab pots daily on an average during this experiment. His average daily catch consisted of less than one live crab and three live lobsters, and of nearly eleven octopus; while he removed daily the corpses or mutilated remains of as many as seven crabs and seven lobsters. Of eight crabs caught daily in his pots, at least seven, on an average, fell victims to the attacks of octopus; and of every ten lobsters caught only three escaped. The number of octopus caught in the pots is not an accurate measure of their actual abundance, because, unlike the crabs and lobsters, they can make their escape from the pots after entering them. In the Bovisand pots the bait was found to have disappeared, although no crabs or lobsters were caught. The capture of one or two octopus, however, in each string of pots shows that the creatures had entered the pots to devour the bait, and then taken 
other forms on the south coast, as well as in an usually heavy fall of oyster spat.

The same conditions must have also affected the octopus, and the abundance of full-grown specimens which was first noticed off our coasts in January, 1899, appears to me to be attributable to that original cause. The warm summers and mild winters which we have experienced during the past few years have also provided the conditions most suitable to a warm-water animal, and have favoured its residence in our inshore waters. In Mr. Allen's paper on the fauna of Salcombe it will be seen that we found the grotto-like nests of the octopus, together with their inmates, in considerable numbers on the shore of Salcombe estuary this year, and others have come across these unpleasant intruders when bathing inshore in Whitsand Bay and elsewhere. I myself found a minute octopus, scarcely larger than a grain of rice $(3.5 \mathrm{~mm}$.), when fishing with a muslin net in Salcombe Harbour in August. This shows that the creature is already established, and reproducing its kind, in our inshore waters, and augurs ill for the shell fisheries during the next few years unless, as we may reasonably expect, a severe winter during the coming season may drive the octopus off shore to deeper water,* or, again, unless remedial measures can be devised for exterminating the animal.

\section{Effects on the Shell Fisheries.}

The extent of the injury caused by the hordes of octopus now infesting our shores may be gathered from the subjoined table. It represents the actual catch of an experienced Plymouth fisherman (Mr. Wm. Roach) during a single week of October, and shows the total number of baited pots put down daily on the grounds, and the catch of crabs, lobsters and octopus. The number of crabs and lobsters killed in the pots by intruding octopus is distinguished from the number of uninjured shell fish. It should be borne in mind that until the last two years the entrance of an octopus into a fisherman's pots was a most exceptional occurrence, and did not happen, as I am credibly informed, more than once or twice a year. Several years might pass before the individual crab fisherman would take a single specimen in his pots.

* Postscript, Nov. 15th. The trawling smacks are now catching large numbers of octopus both off Plymouth (5 miles from shore) and in Start Bay (20 miles S.S.E. of Berry Head). As many as 100 have been taken in one haul in the latter locality. 
TABLE I., showing the Actual Catch of Crabs, Lobsters, and Octopus by a Plymouth fisherman, in Plymouth Sound, during one week in October, 1900, distinguishing the living shell fish from those which had been killed (and often eaten) by Octopus.

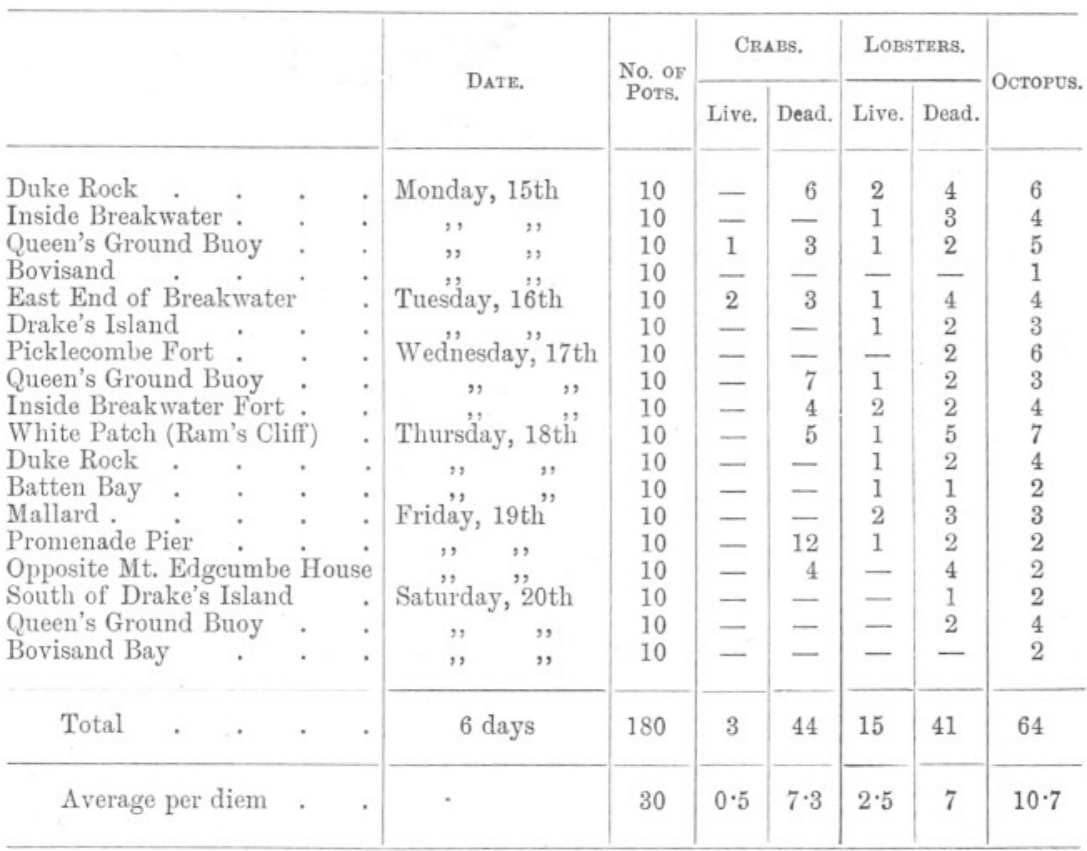

It will be seen that in Plymouth Sound, inside the Breakwater, the fisherman set thirty baited crab pots daily on an average during this experiment. His average daily catch consisted of less than one live $\mathrm{crab}$ and three live lobsters, and of nearly eleven octopus; while he removed daily the corpses or mutilated remains of as many as seven crabs and seven lobsters. Of eight crabs caught daily in his pots, at least seven, on an average, fell victims to the attacks of octopus; and of every ten lobsters caught only three escaped. The number of octopus caught in the pots is not an accurate measure of their actual abundance, because, unlike the crabs and lobsters, they can make their escape from the pots after entering them. In the Bovisand pots the bait was found to have disappeared, although no crabs or lobsters were caught. The capture of one or two octopus, however, in each string of pots shows that the creatures had entered the pots to devour the bait, and then taken their departure. It is, on the other hand, not improbable that the octopus actually caught in one or other of these pots were the same which had eaten the bait in the empty pots.

Be this as it may, the figures in the preceding table reveal in a striking 
manner the enormity of the damage which has been inflicted on the shell fisheries of the Devon and Cornish coasts during the past summer. Although they mark probably the climax of the plague so far as Plymouth is concerned, yet destruction on a similar scale took place for at least six weeks or two months previously, and on a scale not much less serious during the earlier months of the year.

One of the most remarkable phenomena connected with the plague of octopus at Plymouth took place early in September, and appears to indicate that the octopus were moving about in large marauding bands. On Sunday, September 8th, it became known that crabs of unusual size were to be found between tidemarks at Batten and other parts of the eastern side of the harbour, and more than a hundred crabs, 5 to 7 inches in breadth, were picked up in that locality in the single day, as well as larger numbers of the smaller size which normally frequent the tidal zone.*

During the next few days crabs of 4-6 inches breadth were also exceptionally abundant on the shore below the Hoe, near the bathingplace at Tinside, and were gathered by boys who took them away by dozens at a time.

On the western shore, under Mount Edgcumbe, near the "Bridge," we found no specimens exceeding 4 inches in breadth.

The explanation of the appearance between tidemarks of such exceptional numbers of fair-sized crabs is probably that the hordes of octopus had driven the crabs inshore to the shallowest margins as the only avenue of escape. The suddenness of the phenomenon, and its limitation to the eastern and northern sides of the harbour, was possibly due to an incursion into the Sound, through the eastern channel, of roving bands of octopus in search of food, though it is not improbable that the shallower declivity of the bottom and the greater extent of the tidal zone in this region may have facilitated the escape of a larger number of crabs in this part than elsewhere in the Sound.

In order to measure the general damage done to the shell-fish industry on the South Coast during the year, I have had recourse to the Board of Trade's monthly statistics of fish landed. As the practical problems presented are of an immediate character, I have thought it better not to wait until the whole year's returns have been completed, but to base comparisons on the statistics for the six summer months alone during the present and preceding years.

* Mr. W. Demelwick, water bailiff, informs me that from the above-mentioned date to the end of October at least 600 crabs and lobsters were picked up in this locality, viz. about 200 male crabs, 4-7 inches broad; 300 female crabs, $3 \frac{1}{2}-6 \frac{1}{2}$ inches broad; and 100 lobsters, 9-11 inches in length. He adds, "The occurrence was most unusual, and no one remembers such a thing before." 
In the first place, however, it is desirable to review the annual statistics of crabs and lobsters landed on the English coasts since the commencement of the Board's returns, in order to follow the general course of the English shell fisheries during recent years.

The following table shows the numbers of crabs and lobsters returned as landed on the South Coast and on All Coasts of England and Wales annually since 1886 :-

TABLE II., showing the Number of Crabs and Lobsters annually landed (1) on the South Coast, and (2) on All Coasts of England and Wales, from 1886 to 1899, together with the Percentage Ratio in each year of the former to the latter (compiled from the Board of Trade's Returns).

\begin{tabular}{|c|c|c|c|c|c|c|c|c|c|c|c|}
\hline & & \multicolumn{5}{|c|}{ Crabs (thousands). } & \multicolumn{5}{|c|}{ LoBsters (thousands). } \\
\hline & & s. Coast. & & All Coasts. & & r cent. & S. Coast. & & All Coasts. & & r cent. \\
\hline$\{1886$ & • & . $\quad 528$ & $\cdots$ & 2,863 & $\cdots$ & 18 & 325 & $\cdots$ & 452 & $\cdots$ & 72 \\
\hline 87 & . & 630 & $\ldots$ & 4,081 & $\ldots$ & 15 & 399 & $\cdots$ & 518 & $\ldots$ & 77 \\
\hline 88 & . & 635 & $\ldots$ & 4,750 & ... & 13 & 338 & $\ldots$ & 469 & $\ldots$ & 72 \\
\hline 1889 & - & 676 & $\ldots$ & 5,082 & $\ldots$ & 13 & 468 & $\ldots$ & 720 & $\ldots$ & 65 \\
\hline 1890 & . & 744 & $\ldots$ & 4,808 & $\ldots$ & 15 & 596 & $\ldots$ & 922 & $\ldots$ & 65 \\
\hline 1891 & $\cdot$ & 632 & $\cdots$ & 4,612 & $\ldots$ & 14 & 531 & $\ldots$ & 730 & $\ldots$ & 73 \\
\hline$(1892$ & - & 766 & $\ldots$ & 4,521 & $\ldots$ & 17 & 624 & $\ldots$ & 858 & $\ldots$ & 73 \\
\hline 1893 & $\cdot$ & 813 & $\ldots$ & 5,008 & $\ldots$ & 16 & 509 & $\ldots$ & 747 & $\ldots$ & 68 \\
\hline 994 & - & 828 & $\ldots$ & 4,339 & $\ldots$ & 19 & 467 & $\ldots$ & 728 & $\ldots$ & 64 \\
\hline 1895 & - & . 893 & $\ldots$ & 4,501 & $\ldots$ & 20 & 442 & $\ldots$ & 677 & $\ldots$ & 65 \\
\hline & - & - 1,028 & ... & 5,030 & $\ldots$ & $20 \cdot 4$ & 499 & $\ldots$ & 932 & $\ldots$ & $53 \cdot 5$ \\
\hline & - & 911 & $\ldots$ & 4,048 & $\ldots$ & $22 \cdot 5$ & 442 & $\ldots$ & 700 & $\ldots$ & $63 \cdot 1$ \\
\hline 98 & * & . 1,078 & $\ldots$ & 5,628 & & $19 \cdot 2$ & 486 & $\ldots$ & 826 & $\ldots$ & $58 \cdot 9$ \\
\hline 99 & - & . 1,044 & $\ldots$ & 4,918 & & $21 \cdot 2$ & 449 & $\cdots$ & 790 & ... & $56 \cdot 8$ \\
\hline
\end{tabular}

Summary of the preceding Table in Averages for Successive Periods of Four Years.

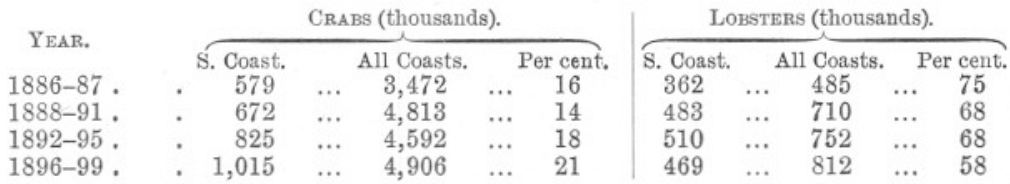

It will be seen, from the summary provided, that on the South Coast the number of crabs annually landed has increased very steadily during the entire period covered by the returns, while the quantities landed on all coasts generally have remained fairly stationary since 1887 . Consequently the percentage of crabs landed on the South Coast has increased during the same period, viz. from 14 per cent. in the quadrennial period 1888-91 to 21 per cent. in the period $1896-9$.

On the other hand, the quantity of lobsters annually landed on the South Coast shows no such steady increase, the maximum having been attained in the years 1890-2, while the total quantity landed on all coasts shows a progressive aggrandisement. Consequently the per- 
centage of lobsters landed on the South Coast has declined from 75 per cent. in $1886-7$ to 58 per cent. in 1896-9.

Unfortunately we have no satisfactory information as to the changes in catching power devoted to this branch of the fishing industry during the period covered by the returns of fish landed. The information contained in column 5 of the collectors' returns in the Annual Reports of the Inspectors of Sea Fisheries (E. and W.) gives a rough indication of the number of boats engaged in crab and lobster fishing since 1892, and I have tabulated the data there given for the two years 1892 and 1899 for the South Coast ports, with the following results :-

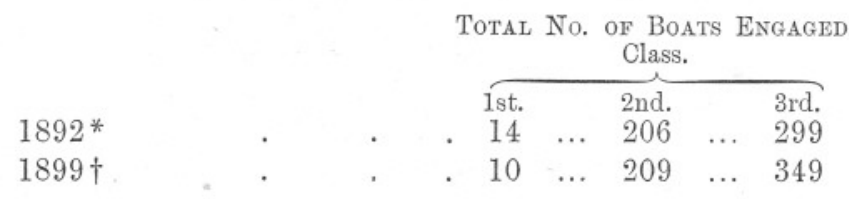

These figures, if reliable, indicate that there has been no appreciable increase in the number of 1 st and 2 nd class boats specially engaged in crab and lobster fishing + on the South Coast during the past eight years. The increase in the number of 3rd class (rowing) boats is probably more apparent than real, as shown by the extraordinary numbers assigned in the returns for Folkestone in 1899, and for Plymouth both in 1892 and 1899 .

Consequently the increase in the returns of crabs landed during the past fourteen years may be taken as indicating an actual increase in their abundance, though this conclusion does not accord with the opinion of Plymouth fishermen whom I have questioned on the point.

The next table (Table III.) shows the average number of crabs and lobsters landed on the South Coast in each month of the year. It is compiled from the monthly returns of the Board of Trade for the entire term of fourteen years, 1886-99. It shows that the catch of shell fish varies regularly with the seasons, being low in the cold months, and high in the warm months. The six most productive months for both crabs and lobsters are seen to be those from April to September.

* Certain obvious errors in the official published figures have been corrected as follows :Kingsdown. - 3rd class boats assigned, 3.

Plymouth.-For " 150 3rd class boats" read " 25 2nd class boats." Helford.-For " 3rd class" read " 2nd class."

+ Corrected as follows:-

Folkestone.-Six 1st class boats and 42 2nd class boats have been eliminated, these being trawlers and line vessels.

Plymouth.-For "100 3rd class boats" read " 20 2nd class boats."

‡ The number of South Coast trawling smacks (which catch a certain quantity of crabs) has not increased 5 per cent. since 1889 (see this Journal, vi. p. 67, Table E), whereas the increase in the annual returns of crabs exceeds 50 per cent. during the same period. 
TABle III., showing the Average Number of Crabs and Lobsters landed on the South Coast of England in each month of the year (compiled from the Board of Trade's Returns for the fourteen years 1886-99); together with the Percentage of each monthly average to the average annual catch for the same series of years.

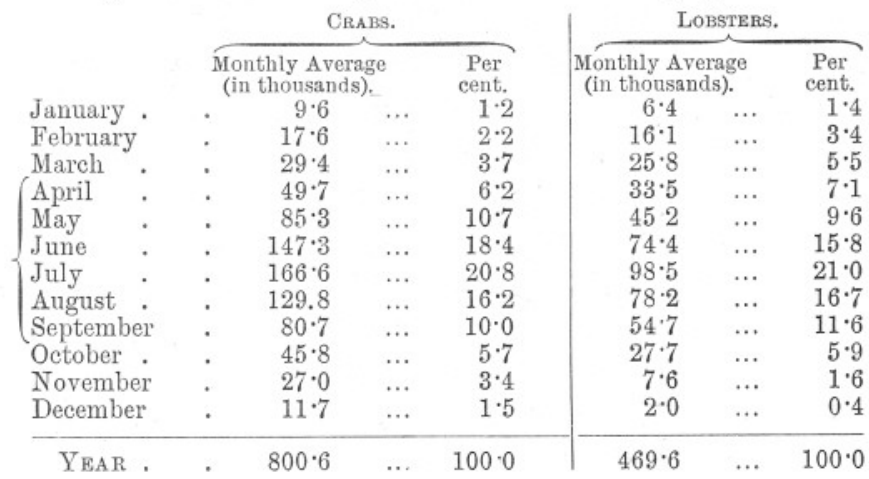

The percentage of crabs landed in the six summer months (April to September) amounts to 82.3 per cent. of the whole, and that of lobsters to 81.8 per cent. of the whole. It follows therefore that statistics based on the returns for the six summer months alone in successive years provide a sufficiently accurate basis from which to compare the productiveness of these fisheries in successive years. Indeed, it is probable that greater accuracy is ensured by this method than by taking the figures for the entire year, since the catches in the winter months depend less on the abundance of shell fish in the vicinity of the coast than on the prevalence or scarcity of stormy weather.

The next table shows the number of crabs and lobsters annually landed during the six summer months on the South Coast from 1886 to 1900 .

TABLE IV., showing the Number of Crabs and Lobsters landed on the South Coast during the six summer months (April to September) in each year from 1886 to 1900 (compiled from the Board of Trade's Returns).

1886
1887
1888
1889
1890
1891
1892
1893
1894
1895
1896
1897
1898
1899
1900

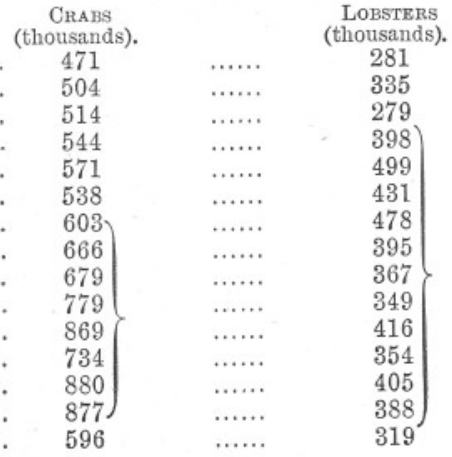


It will be seen from the table that the yearly fluctuations in the returns for these months are almost identical in character with the fluctuations in the returns for the entire year given in Table II. The returns for the six summer months, however, in 1900 are seen to fall far below the returns for many years previously, both for crabs and lobsters, but especially for crabs. The number of crabs landed in 1900 is returned as 596 thousands, and that of lobsters 319 thousands. The returns for the previous year are, for crabs, 877 thousands, and for lobsters 388 thousands. The returns for 1900 accordingly show a diminution of 32 per cent. on the returns of the previous year as regards crabs, and of 18 per cent. as regards lobsters. These decreases are without parallel in the whole period of fifteen years covered by the Board of Trade's statistics, the nearest approach being afforded in the stormy year 1897, when the returns both for crabs and lobsters fell by 15 per cent. below those of the previous year. The number of crabs returned as landed on the South Coast in the summer months of the present year is actually lower than the number returned for any of the previous eight years, and of lobsters for any of the previous eleven years.

These figures therefore show in a marked manner the disastrous effect of the octopus plague on the shell fisheries of the South Coast during the present year. Unfortunately, it is not improbable that the ill effects may continue to be felt for several years to come, since a great destruction of shell fish, both mature and immature, must have taken place without directly affecting the statistics for the present year, though it may be expected to exert a depressing influence on the number of shell fish available for capture in succeeding years.

A feature of considerable interest in these statistics is the suddenness of the fall in 1900, although the first signs of the increase in the number of octopus on our coasts were manifested early in the preceding year. Bearing in mind the fact that the full effects of the plague were already experienced in the Channel Islands and on the French coast during the preceding year, and that there were no indications of any local increase in the numbers of octopus on our coasts prior to 1899, it seems exceedingly probable that the plague on our own coast is due to an actual invasion of octopus from the opposite shores of the Channel. This invasion began in 1899 , but did not reach its height until the present year. The probable cause of the invasion, if this interpretation of the facts be accepted, is not far to seek. Enough is known about plagues in general to justify the statement that while they are in most cases attributable in the first instance to the effects of exceptionably favourable conditions for reproduction and survival, the migrations which subsequently take place are caused by the overcrowding and dearth of food which necessarily ensue in the original locality. I need 
only point to the well-ascertained facts concerning the plagues and migrations of lemmings* and locusts $\dagger$ in support of this statement. +

The information we possess concerning the present plague of octopus points to a precisely similar conclusion-viz, an abnormal multiplication of these creatures on the French shores of the Channel and in the Channel Islands, dating back with some degree of probability to the year 1893, and followed in 1899, when the plague on the French coast had reached its height, by migrations outwards from the overcrowded centres of multiplication.

I have no detailed information as to the devastation effected by these creatures on the French coast (beyond the statement that they have done enormous damage to the shell fisheries in general), but the changes they have already wrought in our own waters are sufficient to show their probable character. In Plymouth Sound they have not only attacked the edible crabs (Cancer pagurus) and lobsters (Homarus vulgaris), but have temporarily exterminated the larger swimming crabs (Portunus puber and depurator) which in previous years have always been found in great abundance in the harbour. During the last few months it has been impossible to obtain more than isolated specimens in the shrimp trawl, although in previous years scores, and even hundreds, at a time could be obtained. In the Laboratory aquarium the octopus attacked and devoured all the specimens of the commoner British octopod, Eledone cirrhosa, which were living in the same tank.

\section{Remedial Measures.}

There is no reason to believe that the present plague of octopus will continue for more than one or two seasons, since the creature would long ago have established itself on our shores if the conditions had been suitable for its permanent residence. The species is a warm-water animal, and belongs, like many other occasional visitants of our southwestern shores, to an assemblage of types which are distributed from the Mediterranean to the southern shore of the English Channel. The extension of these types to the north and east is usually limited by a line drawn from Start Point to the Cherbourg peninsula. As types of this fauna may be mentioned the ormer or ear-shell (Haliotis tuberculata), the crayfish (Palinurus vulgaris), the cotton-spinner (Holothuria nigra), and the pilchard or sardine (Clupea pilchardus). The barrier to the north-east, constituted roughly by the Start-to-Cherbourg line, is largely one of temperature. Eastward of that line the mean yearly temperature

* Collett, Myodes lemmus, its Habits and Migrations in Norway. Christiania Videnskabs-Selskabs Forhandlinger, 1885, No. 3.

+ Munno, The Locust Plague and its Suppression, London, 1900.

\# Cf. Latrer, The Recent Plague of Wasps, Natural Science, iii., Oct., 1893, p. 273; also ef. vi., 1895 , p. 178 . 
of the sea along the whole English coast from Start Point to the Straits of Dover is very slightly in excess of $52^{\circ}$ Fahr., as recently determined by Dickson; * whereas west of that line the mean annual temperature of the coastal waters on the English coast rises from $52^{\circ} \cdot 1$ at the Start to $53^{\circ} .9$ in the Scilly Isles.

On the French coast the mean temperature is naturally somewhat higher than the temperature even of Devonshire and Cornish waters, and is not usually subject to so much depression during the winter months. It is probably this difference which, more than any other, renders impossible the permanent acclimatisation on the Devonshire and Cornish coasts of animals which are common on the opposite shores and rarely found on our own. The warm summers and mild winters which we have recently experienced have enabled the octopus temporarily to maintain themselves on our shores under pressure of the exceptional circumstances prevailing on the French coast; but the normal conditions of temperature will, in all probability, reassert themselves during the next year or two, in which case the disappearance of the octopus will almost certainly ensue.

Great damage to the shell fisheries may unfortunately take place in the meantime, and it is very desirable that the situation should be carefully considered. If the figures given in Table I., p. 265, afford any indication of the injury done to the fisheries in other localities as well as Plymouth, the question arises whether it would not be better for the fishermen to suspend all fishing for crabs and lobsters during the continuance of the plague, and to turn their attention temporarily to other kinds of fishing. By continuing to set their baited pots for shell fish they will obtain very meagre catches of uninjured crabs and lobsters so long as the octopus abound, and will at the same time place a far larger number at the mercy of the octopus without any chance of escape. As shown in Table I., fourteen out of every seventeen crabs and lobsters caught in October fell victims to the octopus, whereas if they had not been imprisoned in the fishermen's pots they would have been free to avail themselves of their natural methods of concealment and protection. Many of those which are now killed in the fishermen's pots would doubtless survive under natural conditions until the octopus disappear again, and would thus add to the breeding stock next year. It is to be feared that this stock, as well as the abundance of young crabs, must have been seriously reduced during the past summer. It is consequently to the fishermen's own interests to avoid all unnecessary waste of those which remain, since it is on them that the fisheries depend for their replenishment during the coming years.

* H. N. Drckson, Q. J. R. Met. Soc., xxv., Oct., 1899. 
The one advantage which results from a continuance of the fishing is that the fishermen are thereby enabled to catch and destroy large numbers of octopus which are taken in their pots, and this in itself is of much importance. If a single fisherman, in the ordinary course of his work, as shown in Table I., can catch sixty-four octopus in a week, an appreciable reduction can be made in their numbers by the labours of ten or a dozen fishermen similarly employed.

On the Continent, however, and especially in the Mediterranean, where these octopods are regularly fished and sold for food, it is found that they can be caught in unbaited earthenware pots or vases, provided these are of a shape and size suitable for the octopus to enter and take shelter in. The pots appear usually to be pitcher-shaped, with a globular body about 12 inches and a neck about 3 or 4 inches in diameter. These are attached by cords to a line at fixed intervals, and the whole is then lowered to the bottom and buoyed for subsequent recognition. The line is hauled up every few days, and a certain number of octopus are found to have taken up their residence in the empty pots. They can thus be removed and killed without involving any sacrifice of valuable shell fish in the process.

In places where the octopus abound, e.g. at Marseilles, three or four men are permanently employed at a small subsidy in the sole work of catching them by the above and similar devices.

The question therefore arises whether similar means could not be used with advantage during the present crisis on the Devonshire and Cornish coasts; and, if so, whether the Sea Fisheries Committees of the two counties might not obtain authority to temporarily subsidise those bona fide crab fishermen who would give up their ordinary mode of fishing to devote themselves for a time to the work of exterminating the octopus by such means.

I hope that by the time these remarks are published I may be in a position to state the results of experiments on these lines which are now in progress in Plymouth Sound. 